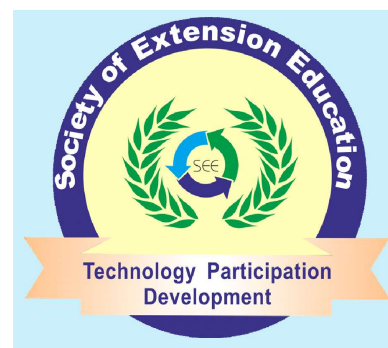

Research Article

\section{Indian Research Journal of Extension Education}

ISSN: 0972-2181 (Print), 0976-1071 (Online)

NAAS Rating : $\mathbf{5 . 2 2}$

Journal homepage: seea.org.in

https://doi.org/10.54986/irjee/2022/jan_mar/8-12

\title{
Knowledge of the Tribal Farmers Towards Organic Turmeric Cultivation in Kandhamal District of Odisha
}

\author{
Biswajit Sahoo', Anindita Saha ${ }^{2}$ and Subha Laxmi Sahoo ${ }^{3}$ \\ 1. PG Scholar, 2. Asso. Prof., Department of Agricultural Extension, Palli Siksha Bhavana, Visva-Bharati University, \\ West Bengal, 3. Ph.D Scholar, Department of Extension Education, Odisha University of Agriculture and \\ Technology (OUAT), Bhubaneswar, Odisha. \\ Corresponding authore-mail : biswajitsahoo599@gmail.com
}

Paper Received on September 01, 2021, Accepted on November 02, 2021 and Published Online on January 01, 2022

\begin{abstract}
Kandhamal is the major turmeric growing district of Odisha. It is the primary cash crop for the financial improvement of the district. Kandhamal Turmeric is an important product and growing in popularity in the organic food market. It has gained an excellent marketplace share in international and local markets and has also received the GI tag on 1st April 2019. The current study was carried out in two blocks of the district to understand the knowledge level of the farmers about organic turmeric cultivation practices. A total of 100 respondents were selected randomly from 4 villages, two villages from each block. Data analysis was done by following proper statistical methods. The result showed that the knowledge index of the farmers towards land preparation, cultural management, harvesting and post-harvesting management was more than 90 per cent. The majority (71\%) of the farmers had a medium level of knowledge towards organic turmeric cultivation and extension agent contact, annual income, land under turmeric cultivation and total landholding showed a significant relationship with the knowledge of the turmeric grow
\end{abstract}

Key words : Cash crop; GI tag; Knowledge index; Cultural management.

India has traditionally been a global leader in the production of spices and as a result of their extraordinary aroma and taste, Indian spices have great demand in the global market. India is the largest producer, consumer and exporter of spices in the world. India utilizes 90 per cent of its production for domestic consumption. About 109 species are notified all over the world where India as a single country grows 63 among them (Ahal Rajeev, 2019). Organic turmeric has won a large amount of importance within the past decade or so mainly due to the increase of the nutraceutical industries worldwide. The nutraceutical properties of turmeric are now widely accepted in modern medicine. The Indian traditional medical systems use turmeric for wound healing, rheumatic disorders, gastrointestinal symptoms, deworming, and rhinitis and as a cosmetic. Hence the demand for organic turmeric has grown up in the local market as more people are turning to natural products for treating lifestyle diseases. With the growing demand and premium in prices, the cultivation of organic turmeric in India has also gained momentum. Farmers are switching towards organic cultivation which is not a new concept for India as traditionally in India cultivation became carried out without using chemical fertilisers 
and pesticides. In India turmeric is growing more than 25 states and among them, Telangana is the largest producer of turmeric in the country with area (50150 ha) and nearly (294560 tons) production which shares 34 per cent of general production in India. Karnataka and Tamil Nadu were second and third in the ranking. Odisha ranks 6th among the states with the area $(27870$ ha) and about (43610 tons) production in the year 201718 [Spice Board of India Ministry of Agriculture Government of India (2017-18)."Turmeric and ginger are the two most important spice crops grown in Odisha and more than $50 \%$ of these crop growers are tribals. Turmeric is the main cash crop grown by Kondha tribes of Kandhamal district. The crop is grown by the tribals with their indigenous methods. Local, Lakadong and Suroma varieties of turmeric are grown by farmers in Kandhamal district Odisha. The crop is mostly produced organically and the farmers get a good return out of this crop. Given the potential of turmeric, the state proposed the Agri Export Zone (AEZ). The zone covers the district of Kandhamal (Babu, et al. 2015). The objective of the study is to analyse the knowledge level of the respondents towards organic turmeric cultivation.

\section{METHODOLOGY}

The study was conducted in Kandhamal district of Odisha. Two blocks i.e. Phiringia and Tikabali were selected randomly. Two villages were selected from each block and in each village 25 tribal farmers associated with organic turmeric farming were selected randomly, thus a total of 100 farmers were selected for this study as respondents. Data were collected from the primary sources (respondents) with the aid of a structured interview schedule consisting of both open and close-ended questions and ex-post factor research design was confined for the research study. The data analysis was done by following several parametric and non-parametric tools like frequency, percentage, mean, standard deviation, multiple regression. In the present study, 51 statements were taken under different cultural management practices and knowledge level of the respondent measure in a two-point scale and score 1 is given to the person who had no knowledge and score 2 is given to that person who knew a particular statement. A standardized knowledge test was developed to measure the knowledge of farmers about organic turmeric cultivation taking into consideration the procedures adopted by Jaganathan et.al. (2012) and Kumar et.al. (2014). However, the knowledge index was calculated by the formula

$$
\text { Knowledge Index }=\frac{\text { Total obtained score }}{\text { Maximum possible score }} \times 100
$$

\section{RESULT AND DISCUSSION}

Practice wise knowledge level of the turmeric growers regarding organic turmeric cultivation.

Land Preparation : From Table 1, it is clear that cent per cent of the turmeric farmers had complete knowledge regarding clean and deep tillage practice and the number of ploughing to bring fine tilth and almost all (99\%) farmers had correctly know about the application of organic manure. Further, it also observed that about 94 per cent of turmeric growers had correctly known about plough across the slope in a hilly area. Whereas 87 per cent, 78 per cent, and 14 per cent of the respondents were knowing solarisation of bed, soil suitable for turmeric cultivation and bed preparation respectively. Hence overall knowledge index regarding land preparation is 90.8 .

Soil Analysis : It was observed that about 76 per cent of farmers had correct knowledge regarding soil analysis and were doing soil testing before planting. They were providing their soil sample to the KASAM organisation or members of this organization were collecting a sample from the farmer's field and send it for testing. Therefore, the overall knowledge index regarding soil analysis is 88 .

Variety : As far as variety is concerned, the local cultivars belong to the local indigenous variety of southern Odisha named Kandhamal Haladi. And About 61 per cent of farmers knew about different improved recommend varieties. Thus the overall knowledge index about variety is 80.5 .

Planting and planting material : Regarding knowledge on planting and planting material, it was found that the majority $(88 \%, 86 \%, 85 \%, 63 \%, 61 \%, 60 \%$ and $47 \%)$ of the turmeric growers possessed correct knowledge about intercropping, correct time/ season of planting, selection of healthy rhizome as planting material, multi-storied cropping, recommended spacing, the Recommended method of planting and preparation of pit respectively. Whereas only 17 per cent of turmeric growers possessed accurate knowledge about recommended seed rate per 
Table 1. Practice wise knowledge level of the turmeric growers regarding organic turmeric cultivation $(\mathrm{N}=100)$

\begin{tabular}{|c|c|c|c|c|}
\hline Statement & No. & $\%$ & KI & Rank \\
\hline Land Preparation & & & 90.8 & IV \\
\hline Clean and deep tillage practice & 100 & 100 & & \\
\hline No of ploughing to bring fine tilth & 100 & 100 & & \\
\hline Soil suitable for turmeric cultivation & 78 & 78 & & \\
\hline Bed preparation & 14 & 14 & & \\
\hline Solarisation of bed & 87 & 87 & & \\
\hline Incorporation of organic manure & 99 & 99 & & \\
\hline Plough across the slope in hilly area. & 94 & 94 & & \\
\hline Soil analysis & & & 88 & $\mathrm{~V}$ \\
\hline Soil testing & 76 & 76 & & \\
\hline Variety & & & 80.5 & VII \\
\hline Recommended variety. & 61 & 61 & & \\
\hline Planting and planting material & & & 81.6 & VI \\
\hline Intercropping & 88 & 88 & & \\
\hline Multi-storied cropping & 63 & 63 & & \\
\hline Selection of healthy rhizome & 85 & 85 & & \\
\hline Recommended seed rate per acre & 17 & 17 & & \\
\hline Correct time/season of planting & 86 & 86 & & \\
\hline Recommended method of planting & 60 & 60 & & \\
\hline Recommended spacing & 61 & 61 & & \\
\hline Preparation of pit & 47 & 47 & & \\
\hline Manure and fertilizer application & & & 72 & VIII \\
\hline Integrated nutrient management & 41 & 41 & & \\
\hline Application of FYM & 91 & 91 & & \\
\hline Recommended quantity of FYM & 30 & 30 & & \\
\hline Time of application of FYM & 36 & 36 & & \\
\hline Recommended bio fertilizer & 12 & 12 & & \\
\hline Neem cake and coir pith application & 54 & 54 & & \\
\hline Application of vermicompost. & 70 & 70 & & \\
\hline Other inputs for soil enrichment. & 18 & 18 & & \\
\hline Water Management & & & 61.6 & $\mathrm{X}$ \\
\hline Critical stage of irrigation & 28 & 28 & & \\
\hline Recommended Irrigation interval & 21 & 21 & & \\
\hline Number of irrigation & 22 & 22 & & \\
\hline Method of irrigation & 22 & 22 & & \\
\hline Cultural Management & & & 99.1 & II \\
\hline Mulching & 95 & 95 & & \\
\hline Weeding & 100 & 100 & & \\
\hline Earthing up & 100 & 100 & & \\
\hline Pest and disease management & & & 69.8 & IX \\
\hline Shoot borer & 57 & 57 & & \\
\hline Application of Neem oil & 45 & 45 & & \\
\hline Burning of field before planting & 22 & 22 & & \\
\hline Rhizome rot & 85 & 85 & & \\
\hline Expose root to sun and remove mud & 21 & 21 & & \\
\hline Appli. of ash and vermicompost & 28 & 28 & & \\
\hline
\end{tabular}

Application of bio-pesticide

Harvesting

Maturity and harvesting indices

Optimum time for maturity

Different method of harvesting

Rhizomes left in the field

Preservation of mother rhizome as seed

Post-harvest management

Boiling of finger and mother rhizome

Optimum time required for Boiling

Thickness of spreading of rhizomes

Optimum time required for drying

Curing

Polishing

Grading

acre. Therefore, the overall knowledge index about planting and planting material is 81.6.

Manure and fertilizer application/nutrient management: Concerning nutrient management, about 91 per cent of the respondents knew farmyard manure (FYM), along with 36 per cent and 30 per cent of farmers had proper knowledge about the time of application of FYM and recommend a quantity of FYM respectively. Further, it was also observed that about 70 per cent and 54 per cent of the turmeric farmers had correctly known about the application of vermicompost and Neem cake and coir pith application of recommended quantity respectively. Whereas only 41 per cent, 18 per cent and 12 per cent knew integrated nutrient management, recommend bio fertiliser and other input for soil enrichment respectively. Hence overall knowledge index regarding manure and fertilizer application/nutrient management is 72 .

Water management : From Table 1 it was found that the respondents were found to possess low-level knowledge about the critical stage of irrigation (28\%), number of irrigation (22\%), method of irrigation (22\%) and recommend irrigation interval $(21 \%)$. Thus, the overall knowledge index about water management is 61.6.

Cultural management : Under the cultural management cent per cent of respondents had knowledge regarding weeding and earthing up followed by 95 per cent of farmers were knowing to mulch. Therefore, the overall knowledge index regarding cultural management is 99.1 . Pest and disease management : From Table 1 it was observed that major 85 per cent of the turmeric growers 
knew rhizome rot, 57 per cent of farmers had correct knowledge about shoot borer whereas 45 per cent, 28 per cent, 22 per cent, 21 per cent and 20 per cent farmers had proper knowledge about the application of neem oil, application of wood ash and vermicompost @2t/ha, burning of the field before planting, expose root to the sun and remove mud and application of biopesticide (Trichoderma Viride, Beuveria Bassian and Pseudomonas) respectively. Hence the overall knowledge index about pest and disease management is 69.8 .

Harvesting : It was worthwhile to be noted that 100 per cent respondents had knowledge about the optimum time required for the maturity of turmeric almost all about 99 per cent of the respondents had knowledge about preservation of mother rhizome as seed along with 94 per cent of the respondents were properly know how to increase the curcumin content i.e. rhizomes left in the field after cutting leaves and before boiling, 92 per cent of the respondents were correctly aware of maturity and Harvesting Indices and only 40 per cent farmers were knowing different methods of harvesting. Therefore, the overall knowledge index regarding harvesting is 92.5 .

Post-harvest management : It's quite interesting to observe that it was evident from the table that 100 per cent of respondents were knowing various post-harvest management practices those are boiling of finger and mother rhizome separately, the optimum time required for Boiling, the thickness of spreading of Rhizomes for drying, the optimum time required for complete drying under the sun, curing, polishing, grading. Thus, the overall knowledge index of post-harvest management is 100.

Based on the knowledge index (KI) ranking was done accordingly. From Table 1 it was found that the overall knowledge index regarding post-harvest management is 100 , regarding cultural management is 99.1 and regarding harvesting is 92.5 . Hence ranked as I, II, III respectively. A similar ranking was found in the study conducted by Naik et.al. (2009).

Table 2. Distribution of the respondents on the basis of their overall knowledge level $(\mathrm{N}=100)$

\begin{tabular}{lll}
\hline Knowledge level & No. & $\%$ \\
\hline Low $(\leq 82)$ & 17 & 17.0 \\
Medium $(83-91)$ & 71 & 71.0 \\
High $(>91)$ & 12 & 12.0 \\
Total & 100 & 100.0 \\
\hline
\end{tabular}

Mean $=86 \quad$ S.D $=4$

Overall Knowledge level of the turmeric growers regarding organic turmeric cultivation: It is observed from the Table 2 majority 71 per cent farmers had a medium level of knowledge followed by 17 per cent and 12 per cent of respondents were having a low and high level of knowledge about organic turmeric cultivation. (Gopiram 2005; Shankar 2006; Singh et.al. 2012; Rao 2016). These studies supported the findings of the present study and proved that majority of the turmeric growers had a medium level of knowledge.

Correlation analysis of independent variables with knowledge: The Table 3 revealed that out of 11 variables 5 variables shows correlation with the knowledge level of the respondents and the remaining six shows no significance. The correlated independent variables show positive significance at 0.01 level of

Table 3. Coefficient of correlation analysis of independent variable with knowledge and Multiple regression analysis of the independent variables with knowledge $(\mathrm{N}=100)$

\begin{tabular}{lcccc}
\hline Variables & $\begin{array}{c}\text { Coefficient of } \\
\text { correlation (r) value }\end{array}$ & $\begin{array}{c}\text { Regression } \\
\text { co-efficient }\end{array}$ & $\begin{array}{c}\text { Standard } \\
\text { error }\end{array}$ & $\begin{array}{c}\text { 't' } \\
\text { value }\end{array}$ \\
\hline Age & $0.045^{\mathrm{NS}}$ & 0.036 & 0.047 & 0.769 \\
Education & $-0.012^{\mathrm{NS}}$ & 0.389 & 0.481 & 0.809 \\
Family type & $0.191^{\mathrm{NS}}$ & 1.464 & 0.919 & 1.591 \\
Housing quality & $0.06^{\mathrm{NS}}$ & 0.530 & 0.927 & 0.571 \\
Total land holding & $0.224^{*}$ & $-0.299^{*}$ & 0.149 & -2.011 \\
Land under turmeric cultivation & $0.519^{* *}$ & $1.916^{*}$ & 0.937 & 2.043 \\
Social participation & $0.171 \mathrm{NS}$ & 0.431 & 0.471 & 0.916 \\
Experience & $0.035 \mathrm{NS}$ & 0.055 & 0.050 & 1.090 \\
Annual Income & $0.486^{* *}$ & $5.6 \mathrm{E}-05^{*}$ & $2.14 \mathrm{E}-05$ & 2.612 \\
Extension agent Contact & $0.547^{* *}$ & $0.937^{* *}$ & 0.204 & 4.573 \\
Mass media contact & $0.262^{* *}$ & 0.270 & 0.155 & 1.742 \\
\hline
\end{tabular}

$\mathrm{R}^{2}=0.521 \quad$ Multiple $\mathrm{R}=0.722 \quad * *$ Significant at the 0.01 level

*Significant at the 0.05 level 
probability these were land under turmeric cultivation, annual income, extension agent contact and mass media contact. A positive correlation was also found in the case of total landholding with a 0.05 level of probability. The positive significance means the knowledge level of the respondents increases with an increase in these variables. The significant and positive relationship between mass media contact and knowledge was also reported by Jaganathan et.al. (2012), Kumar et.al. (2014) and Naik et.al. (2009)

Multiple regression analysis of the independent variables with knowledge: The multiple regression analysis of the independent variable with the knowledge level of the farmers are presented in Table 3. The table revealed that four variables show significance with knowledge level such as Total land holding shows negative significance at 0.05 level of probability, land under turmeric cultivation and annual income shows positive significance at 0.05 level probability, extension agent contact shows highly and positive significance at
0.01 level of probability. Whereas other variables did not affect it.

\section{CONCLUSION}

From the study, it was concluded that the majority 71 per cent of farmers had a medium level of knowledge about organic turmeric cultivation. And farmers had good knowledge about post-harvest management. The indigenous technical knowledge acquired by the farmers needs to be tested and refined with modern techniques. This will further help the farmers to enhance their capacity building, especially in the trading sector. As the farmers had a good knowledge of post-harvest management there is a need for integrating this knowledge with the marketing component which will help in getting benefit from their organic turmeric which gets the GI tag for the region.

\section{CONFLICTS OF INTEREST}

The authors declare that they have no conflicts of interest.

\section{REFERENCE}

Ahal, Rajeev (2019). Business model: organic turmeric and ginger : Deutsche gesellschaft für internationale zusammenarbeit (GIZ) GmbH., pdf retrived from http://www.birdlucknow.in/wp-content/uploads/2020/03/18-Organic-Ginger-and-TurmericBusiness-Model.pdf

Babu, Naresh; Shukla, A.K.; Tripathi, P.C. and Prusty, Monoranjan (2015). Traditional cultivation practices of turmeric in tribal belt of Odisha: Journal of Engineering Computers \& Applied Sciences, 4 (2) :52-57.

Gopiram, M. (2005). Knowledge and adoption of turmeric farmers in Kadapa district of Andhra Pradesh. M. Sc (Ag.) Thesis. Acharya N.G. Ranga Agricultural University, Hyderabad, India.

Jaganathan, D. (2010). Knowledge level of farmers on organic farming in Tamil Nadu. Indian Res. J. Ext. Edu., 12 (3) : $70-73$.

Kumar, Sarvesh; Singh, S.R.K and Sharma, R.C. (2014). Farmers knowledge level on organic cultivation in Madhya Pradesh. Indian Res. J. Ext. Edu., 14 (3) : 131-133

Ministry of commerce and industry, Govt. of India. Spices Board India Major Spice/state wise area and production of spices retrieved from https://www.indianspices.com/sites/default/files/majorspicestatewise pdf

Naik, H.M. (2009). Knowledge level about organic farming in Haryana. Indian Res. J. Ext. Edu., 9 (1):50-53

Rao, N.S., (2016). A study on knowledge and adoption of turmeric farmers in Guntur district of Andhra Pradesh. M.Sc (Agril.) Thesis, Acharya N.G. Ranga Agricultural University.

Shankar, M.V. (2006). Adoption of recommended cultivation practices of turmeric by the turmeric growers in Satara district. M.Sc. (Agri.) Thesis, Mahatma Phule Krishi Vidyapeeth, Rahuri.

Singh, P.; Jat, H.L. and Sharma, S.K. (2012). Factors affecting knowledge of farmers about recommended production technologies of cluster bean cultivation in arid area of Rajasthan. Indian Res. J. Ext. Edu., Special Issue (Volume II) : 59-61 